\title{
Palliative care: community nurses' perceptions of quality
}

\author{
Lynn Austin, Karen Luker, Ann Caress, Chris Hallett
}

\begin{abstract}
Objectives-To identify community nurses' perceptions of quality care provision for patients requiring palliative care. Design-Semi-structured interviews were conducted with community nurses working within the district nursing service. An adaptation of Flanagan's critical incident technique was employed to elicit factors associated with high or poor quality palliative care. Interviews were tape recorded and transcribed. Data were analysed using thematic content analysis, recurrent themes being agreed by the research team.
\end{abstract}

Setting-One community healthcare trust.

Subjects-62 members of the district nursing team (grades B-H).

Results-Respondents recounted the context in which high quality palliative care could be provided, the actions required, and the indicators that suggested the desired level of care had been achieved. Key factors identified were: the early referral of patients to the district nursing service, family circumstances, the availability of time, the accessibility of services and equipment, and the relationship with other healthcare professionals and informal carers. There was a general view that a positive outcome had been achieved when patients retained control over their circumstances and died a peaceful death, in the place of their choice, supported by their family.

Conclusions-Community nurses were able to articulate clearly the essential components of high quality care. Whilst these factors do not represent a comprehensive list, they are put forward as a useful starting point for standard setting and subsequent audit.

(Quality in Health Care 2000;9:151-158)

School of Nursing, Midwifery and Health Visiting, University of Manchester, Coupland III Building, Oxford Road, Manchester

M13 9PL, UK

L Austin, research fellow

$\mathrm{K}$ Luker, professor of

nursing

A Caress, lecturer

C Hallett, lecturer

Correspondence to:

L Austin

ynn.austin@man.ac.uk

Accepted 30 March 2000
Keywords: palliative care; community nursing

Providing high quality care has dominated policy issues at a national level for the last decade and continues to receive a high profile in current government initiatives. ${ }^{12}$ Despite the activity in the field of quality improvement, there is little reliable evidence regarding community nurses' perceptions and definitions of quality care provision (see box 1 for operational definitions of community nurses). Indeed, with a few notable exceptions, ${ }^{3}$ the work of community nurses in general is poorly described.
While some recent studies have been undertaken with regard to the work of community nurses and patients requiring palliative care, ${ }^{56}$ these are generally on a small scale and are dependent on quantitative methods or are limited in perspective. For example, while the views of community nurses are represented, those of community nurses of other grades working within the district nursing service have not been explored. Much of the published literature predates the major changes that have impacted on the work of community nurses, although useful summaries of the "state of play" in palliative care prior to these changes have been published. ${ }^{8-11}$ Perhaps the most radical changes that have taken place can be attributed to the Community Care $\mathrm{Act}^{12}$ enacted in 1993 which resulted in the transfer of some nursing work to social services. Notwithstanding the debate surrounding this division, ${ }^{13}$ the nature of the work of community nurses has changed. An outline of palliative care services in the UK is shown in box 2 .

In addition to the division between healthcare workers and social services, other recent changes have affected the context in which community nurses provide care. The emphasis on providing care in a patient's home and the early discharge of patients from hospital who are more sick has placed increasing pressures on the district nursing service. The introduction of the market economy into the NHS, with a purchaser/provider split, has altered the way in which community nurses work. Although

Key messages

- Community nurses were able to identify many factors that contribute to the provision of high quality palliative care for patients. Important components included: (a) the early referral of patients to the district nursing service; (b) family circumstances that support the care of patients in their own home; (c) sufficient time to meet more than the physical aspects of patient care; (d) availability of equipment and support services.

- Community nurses invested a considerable amount of time in the formation of positive relationships with patients, families, healthcare professionals, and formal carers to facilitate the provision of good care.

- The general view was that a positive outcome had been achieved if patients retained control over their circumstances and had a peaceful death in the place of their choice. 
A community trust is the employing authority for district nursing services within a given location.

The district nursing service provides care for patients in a home setting and includes the following personnel:

- District nurse: a registered nurse with an additional qualification in district nursing

- Community nurse: a registered nurse working within the district nursing service who does not possess a district nursing qualification.

- Nursing auxiliary: a care worker who does not possess a nursing qualification but works in a supportive role to the nursing staff under the supervision of a registered nurse.

Clinical nursing related posts range from grade $\mathrm{B}$ (nursing auxiliary) to grade I (the most senior level for registered nurses working in a clinical setting).

The term "community nurse" is used in this paper to include all of the above members of the district nursing team.

Box 1 District nursing services.

changes in government policy have produced a shift towards more collaborative methods of working, it remains imperative for healthcare workers to demonstrate their value and the uniqueness of their role. This is set to continue, given the establishment of primary care groups who will ultimately be responsible for defining and organising service delivery in a community setting.

The last decade has seen an expansion in the services involved in the provision of palliative care, not least the Macmillan nursing service (box 2). This, coupled with developments in the hospice movement where care provision is now more flexible, has increased the number of available services on which the community nurse is able to draw.

There are no recent studies that seek explicitly the views of community nurses regarding the factors that facilitate the provision of high quality palliative care. The need for the district nursing service to provide clear indicators of the quality of service they provide has been given increasing impetus in the current climate. ${ }^{414}$ The recent Audit Commission report ${ }^{14}$ on district nursing services identified a need for "robust methods of measuring standards of clinical quality (in terms of processes and health outcomes). Clinical audit is a key quality improvement process which enables practitioners to examine their practices against standards based on evidence of good practice from research or consensus."

The lack of audit activity may be related in part to the absence of good practice standards. A re-examination of the nursing role in the provision of high quality care is therefore timely as this goes some way towards obtaining consensus regarding the required evidence of good practice.

The findings presented here form part of a wider study with a remit to identify community
Palliative care services within the UK are provided by both the voluntary and statutory sectors. Over the last decade there has been an increasing emphasis on collaborative working between these two sectors to ensure integration of services. Care provision varies according to geographical location, although the current impetus is for equal access to services for patients regardless of where they live. ${ }^{7}$ Services commonly employed in the provision of palliative care include:

- NHS hospital palliative care teams.

- Primary care teams (including the district nursing services).

- Hospices which offer short stays for patients for symptom control or rest.

- Macmillan nurses who offer advice on symptom control to other healthcare professionals and provide information and support to patients and their carers.

- Marie Curie nurses who provide nursing care for patients in the community, especially at night so that carers are able to rest.

Box 2 Palliative care services in the UK.

nurses' perceptions and definitions of quality care provision for three patient groups-those newly discharged from hospital, those with chronic wounds, and those requiring palliative care. This paper presents respondents' views regarding the provision of palliative care.

\section{Methods}

POPULATION AND SAMPLE

The study was conducted in three localities that make up one community health care trust. Interviews were conducted with 62 staff (grades B-H) between March and June 1998. A senior nurse manager randomly selected community nurses for interview from the staff database as access to these data is restricted to personnel employed by the community trust. Randomisation was effected by the use of computer generated random numbers. Respondents were informed of the study by a letter from the research team and were invited to participate in interviews. All participants were assured of anonymity. The wishes of community nurses who did not want to take part in the study or have the interview tape recorded were respected.

\section{STUDY DESIGN}

A critical incident approach ${ }^{15}$ was employed to elicit factors associated with the provision of high quality or poor care. The particular strength of this technique is that it seeks information on both the positive and negative aspects of care provision from those most closely involved-in this instance, community nurses. The specific questions were:

"Can you tell me about a recent occasion on which you had contact with a patient requiring palliative care which you think went particularly well?" 
"Can you tell me about a recent occasion on which you had contact with a patient requiring palliative care where you thought things could have gone better?"

Respondents were encouraged to provide detailed descriptions of the incidents they selected so that factors that contributed to high or poor quality care could be identified. The flexible approach to the critical incident technique described by Norman et $a l^{16}$ was adopted as this permitted respondents to summarise their experience overall if they were unable to recall a particular incident.

DATA COLLECTION AND ANALYSIS

Interviews lasted between half an hour and one hour and were conducted by a team of four researchers. Respondents recounted situations in which they had been able to provide a good service for patients requiring palliative care and situations in which this had not been possible. Whilst it is acknowledged that the terms "palliative care" and "terminal care" have specific definitions, respondents tended to use both terms interchangeably and this is reflected in the text. Most of the interviews were tape recorded but in four cases notes were taken as the interviewee did not wish to be recorded. Interviews were transcribed prior to data analysis. In total, the respondents described approximately 120 incidents relating to palliative care.

Copies of the full transcripts were circulated to each member of the research team. The transcripts were divided into case types (wound care, hospital discharges, palliative care); the data presented here relate only to palliative care. The transcripts were analysed inductively with each researcher undertaking preliminary analysis and identification of key themes for their own interview data. Subsequent meetings of the research team were used to agree coding categories for factors that contributed to or prohibited the provision of high quality care. These coding categories were then applied to the full data set. Given the impetus for the study was the identification of factors that contribute to the provision of high quality care that could be used as quality indicators in subsequent audit, data analysis and presentation focused on areas in which there was broad consensus amongst respondents.

\section{Results}

Respondents spoke in terms of the context in which care of a high quality could be provided, the actions required to provide good quality care, and the indicators that suggested that the desired level of care had been achieved. These are analogous with the Donabedian structure, process, and outcome categories commonly employed by the nursing profession in definitions of quality-for example, the dynamic standard setting system developed by the Royal College of Nursing. ${ }^{17}$ The findings are summarised in a "structure/process/outcome" format in table 1 and are detailed below.
STRUCTURES

Early referral of patients

The early referral of patients to the district nursing service was viewed as essential as it facilitated contact with the family at a critical stage and ensured that the community nurse could make an assessment of the patient's and family's needs and make suggestions as to the kind of support they might wish to receive:

"I like to get to know them while they are reasonably well really and build up a relationship then with them. And when they do become terminally ill they tend to accept more and trust you and see that they do know you and you do know what you're doing."

Situations in which the district nursing service had not had early contact with the patient could present difficulties as this created a "crisis" situation in which the provision of ideal care was not always achievable:

"I much prefer to be involved very early on, right from diagnosis. Now (some GPs) tend to wait until they've got a problem, either it's pain control or the patient is vomiting, and they're not getting on top of the vomiting or the pain control or whatever aids and adaptations to the house, so you are brought in a lot later, which I think is a problem."

\section{Family circumstances}

Family circumstances played a central role. Respondents used terms such as a "good home" to work in. Generally, this was a home in which the family was actively involved in care, receptive to the community nurse and other services, and willing to adapt the home to meet the patient's needs:

"It was lucky with this particular family that they had expressed a wish to be involved where possible. I mean you could tell really as soon as you went into the home that they would, whether it was little bits of meals that they were making for-or they had even attempted to wash and change a night dress, just personal things and attending to her hair."

Relationships within the family also played a notable role. Patients who lived with or had support from family members were deemed more likely to receive better care. This related in part to practical matters such as someone being there who could help the patient with their physical needs or provide services such as cooking meals. It also contributed to patients' general well being by providing emotional support which enabled patients to stay at home in familiar surroundings if this was their wish.

Conversely, difficulties were encountered if there appeared to be some friction within the family or if the family was hostile to the district nursing and other services. Care provision was also problematic in situations in which the patient or family appeared to be unaware of the diagnosis or prognosis, not least because of the implications with regard to drawing in other support services.

Caring for patients was also more difficult if relatives were willing but unable to provide care, or felt unable to cope. Respondents made reference to family members who lived some distance from the patient or had other commitments. In "crisis" situations patients were 
Table 1 Summary of structures, processes, and outcomes

\begin{tabular}{|c|c|c|}
\hline $\begin{array}{l}\text { Structures } \\
\text { (actual services/equipment required and other factors } \\
\text { which need to be in place) }\end{array}$ & $\begin{array}{l}\text { Processes } \\
\text { (actions required by the community nurses) }\end{array}$ & $\begin{array}{l}\text { Outcomes } \\
\text { (indicators that the desired level of care has been achieved) }\end{array}$ \\
\hline $\begin{array}{l}\text { Early referral } \\
\text { Mechanism for the early referral of patients to } \\
\text { the service } \\
\text { Family circumstances } \\
\text { Patient and/or family who: } \\
\text { - are aware of the diagnosis } \\
\text { - have a strong supportive relationship } \\
\text { - are receptive to district nursing and other } \\
\text { services } \\
\text { - are receptive to advice regarding care } \\
\text { - agree to utilising support equipment in the } \\
\text { home and adapting the home to meet the } \\
\text { patient's needs } \\
\text { - are keen to participate in patient care } \\
\text { Availability of time } \\
\text { District nursing service: } \\
\text { - Nurses with expertise in palliative care } \\
\text { - Staffing levels which ensure that staff have } \\
\text { time to meet the patient's physical and } \\
\text { psychological needs } \\
\text { Availability of services and equipment } \\
\text { Access to support services e.g.: } \\
\text { - Hospice } \\
\text { - Macmillan nurses } \\
\text { - Marie Curie services } \\
\text { - Supportive and accessible GP } \\
\text { Access to equipment e.g. } \\
\text { Beds/mattresses/hoists/syringe drivers }\end{array}$ & $\begin{array}{l}\text { Relationship with the patient and family } \\
\text { The district nursing service: } \\
\text { - establishes early contact with the patient/family to } \\
\text { assess their needs/expectations } \\
\text { - provides continuity of care for the patient by } \\
\text { limiting the number of district nursing staff caring } \\
\text { for the patient } \\
\text { - plans and coordinates care for patient/family } \\
\text { - ensures the patient/family are aware of services } \\
\text { available to them } \\
\text { - provides support for both the family and the } \\
\text { patient } \\
\text { - provides care in a way which is consistent with the } \\
\text { patient's/family's wishes } \\
\text { - supports the family following the patient's death } \\
\text { (e.g. by attending the funeral, making post } \\
\text { bereavement visit(s)) } \\
\text { Relationship with other healthcare professionals and } \\
\text { formal carers } \\
\text { - maintains a positive working relationship with } \\
\text { other healthcare professionals and formal carers }\end{array}$ & $\begin{array}{l}\text { Patients/family and the district nursing team } \\
\text { The patient: } \\
\text { - receives care in the place of their choice } \\
\text { - retains some control over their circumstances } \\
\text { - maintains some quality of life } \\
\text { - has their symptoms controlled to a level which is } \\
\text { acceptable to them } \\
\text { - dies in the place of their choice } \\
\text { The family: } \\
\text { - feel able to cope with caring for the patient in the place } \\
\text { of the patient's choice } \\
\text { - feel the patient was comfortable and retained their } \\
\text { dignity whilst receiving palliative care } \\
\text { - have the opportunity to discuss concerns/anxieties with } \\
\text { a member of the district nursing service } \\
\text { The district nursing team: } \\
\text { - feel the patient was comfortable and retained their } \\
\text { dignity whilst receiving palliative care } \\
\text { - feel they have done a good job } \\
\text { - have cared for the patient in the way they would wish } \\
\text { to be cared for } \\
\text { - have felt able to provide care "over and above" that } \\
\text { required to meet the patient's/family's immediate needs }\end{array}$ \\
\hline
\end{tabular}

sometimes admitted to institutionalised care even though this conflicted with their expressed wishes. The decision to admit the patient to another setting was reported as often being made in isolation by the general practitioner:

"One morning I got a phone call from the GP saying he had admitted her into the hospice, not because he felt that it was appropriate or even that she wanted it, but the sons just felt that . . it was getting too much for them and they were worrying about her because they weren't with her and, you know, but because we weren't providing sits every night they were worried she might die on her own. I was upset because I felt they hadn't given me a chance; if they'd said can we provide more care then we could have done."

Availability of time

A considerable influence on the patient's care was the amount of time available. However, staff were at pains to ensure that they did not appear to be rushed whilst they were with the patient:

"I felt the nursing staff gave them space-as much as they needed - they never rushed, even if they didn't have anything to do, you know, physical, they'd spend time with the lady and the family."

Although desirable, this was not always possible. Respondents commonly mentioned that, as a consequence, less time was available for other patients or greater demands were placed on other staff.

Nonetheless, there was a general feeling that the needs of patients requiring palliative care came first and that, at the very least, the patient's physical needs should be met. In fact, respondents often referred to care provided that might be considered "over and above" that required for the patient's immediate nursing needs-for example, tailoring the working day so that the patient could be visited at a specific time, altering shift patterns so that key staff could be available at critical times, and even visiting patients on days off. This again relates to the close bond formed with this group of patients:

"When you're a district nurse and you get involved in palliative care, sometimes you get that you become part of the family and they rely on you and you know if they've become friends ... It's really nice because you get involved. Sometimes you go a little bit overboard... I always nurse people how I think I would like to be nursed myself . . like this business of going washing his hair (no longer a recognised nursing duty) so I'd go at 7 o'clock and do it."

Forming a relationship with the family, making time available, and carrying out all aspects of patient care was highly prized by nurses and was a source of work satisfaction. This was linked by some to the erosion of their role since the division between health and social care. In these circumstances community nurses felt more able to justify their interactions with patients, the provision of what they viewed as holistic care (meeting patients' physical, social and psychological needs) being highly desirable:

"I haven't got a problem when it comes to nursing the terminal patients. I find that quite rewarding really because it's the one time as a district nurse you're back to doing your basic hands on. That's the only time we do the basic hands on general care. So yeah, I do, it's awful to say but I do enjoy when you have a terminal patient because everyone becomes involved. You get to know the patient."

However, some felt the pressure to discard what might be viewed as social care was such that even patients requiring palliative care could not be afforded this luxury:

"I used to say it's one of the very few fields that you could have holistic care, true holistic care. I 
don't feel like that now. I feel sort of, going in, even to palliative care, I mean I would always say that's been my forte. I'm going in now to people who I'm giving palliative care to, you say, well, you know, getting up, having a wash and getting dressed in the morning isn't the nurse's job so that goes over to social services. I feel that's not a good step."

\section{Availability of services and equipment}

Equipment: The dependence on equipment had particular relevance given the general aim of the district nursing service to provide care in the patient's home. Whilst much of the equipment required was usually available, difficulties could arise. The provision of equipment was particularly problematic when patients required items at short notice-for example, if they were referred at a weekend or in a "crisis" situation - as access to equipment out of hours was less straightforward.

Hospice, Macmillan and Marie Curie services: Working in partnership with patients and their carers enabled the community nurses to draw upon the plethora of services available to support patients. In addition to the Macmillan nurses, there were both hospice and Marie Curie night sitters and "hospice at home" services. The utilisation of these services was often orchestrated by the community nurse. While many support networks were in place, their availability was, nonetheless, dictated by the demands being placed on them at any one time:

"Sometimes people need, maybe need a bit more help at home and you've not been able to necessarily offer it . . . I mean if somebody is really poorly then the last few days of their life, sometimes we've had a sitter in every night, and that has been OK. But you know there are occasions when maybe there's a lot of demand on the service and you can't always offer that, so that's a bit sad."

Overall, community nurses valued the Macmillan service in terms of the support they could provide for patients and as a resource for staff. The focus of the work of Macmillan nurses was viewed as the psychological support of patients, an aspect of care interviewees did not always feel able to provide because of the demands placed on their time:

"I feel that, you know, I can counsel people but sometimes you've not always got the time when you've opened up ... so I do feel that like the Macmillan service, I use them an awful lot, I find them invaluable because I have had experience, myself personally with them, so that, you know, I would use them for advice and support for myself and for the families."

Whilst many of the nurses interviewed considered themselves to have expertise in palliative care, the Macmillan nurses were used as a source of specialist advice or support. In the main this was welcomed although some respondents alluded to the fact that this could lead to some duplication of effort or lack of continuity of care because of the number of personnel involved.

GP services: The role of the GP was critical in determining how successfully the patient could be cared for. Many respondents noted that they had positive working relationships with the GPs although, as already noted, difficulties could be encountered if patients were not referred at an early stage. In general, GPs did not appear to be routinely involved in the day to day care of patients and were only likely to be contacted by the district nursing service when the patient required some form of symptom control, most commonly analgesia. Problems emerged when the GP's view of the need for symptom control differed from that of either the nurse or the patient. A number of respondents recalled incidents in which this had led to patients appearing to be distressed or in pain:

"We felt this man should have a syringe driver to control his pain ... we wanted the syringe driver mainly for some sort of sedation that would settle this man, allow him to die peacefully, and she (his wife) would be-have a last couple of days with him and remember something peaceful rather than the constant tussle she was having trying to keep this man in bed. The GP didn't want to put the syringe driver up, for whatever reason, she kept saying he didn't need it ... So we ended up-on the day the man died - she finally said alright, you can put a syringe driver in ... we finally got the syringe driver set up at something like 7 o'clock in the evening and he died in the early hours of the following morning and to me that wasn't acceptable."

PROCESSES

In addition to structural considerations, the processes of care provision that contributed to high quality care were apparent from the interviews with community nurses. These processes hinged on the development of a positive relationship with the patient, the family, other healthcare professionals, and formal carers.

Relationship with the patient and family

It was considered to be good practice to ensure continuity of care for the patient by keeping the number of community nurses involved to a minimum. This enabled staff to establish a good rapport with the family and aided the establishment of trust between the nurse and the family. This relationship aided the planning and provision of care and helped to ensure that care provided was consistent with the wishes of the patient and family. Indeed, a great deal of emphasis was placed on caring for the family as much as the patient by all grades of staff:

"I think just generally getting on with the whole family rather than just seeing to the patient then I'd go and have a chat with the carers and see how they're coping because obviously it affects them as much. You know, not just going into the patient$i t$ 's the family as a whole. I mean that was it, a good relationship."

Anything which could be done to alleviate the distress of carers was valued. In some cases this necessitated staff "managing the environment" by contriving situations in which they could speak to a family member when the patient was not present. Care of the family often extended beyond the time of the death in the form of attendance at the patient's funeral and bereavement visits. 
Relationship with other healthcare professionals and formal carers

The relationship in place with other healthcare providers and formal carers influenced the provision of care. If a good relationship between the district nursing service and other agencies could be maintained, this made it easier to introduce support from these services when it was deemed appropriate. In this respect, the district nursing service appeared to act as the "lynch pin" or "gatekeeper" to services provided by other professionals. This was explicitly stated by a number of respondents who viewed part of their remit to be a coordinating role, assessing the need for other services and introducing these when considered necessary. The importance of good communication leading to a successful multidisciplinary approach was stressed:

"It was nice how all the services pulled together. And within a day we had all the equipment that we needed. The rise and fall bed, hoist, everything in the house. We had hospice at home team in offering sits. We had Marie Curie involved. We also had rapid response involved. This all took over a period of maybe a fortnight before he died but everybody worked really very closely together and it worked very well ... good coordination, good communication. Everybody let each other know what they could do, what input they could provide, and it was all coordinated really from the district nursing service."

OUTCOMES

The primary function of palliative care was to maintain the patient's quality of life up to the time of their death. Patients who retained control over their circumstances were cited as positive examples and death was seen as more acceptable if patients were pain free, comfortable, and had their dignity retained. Ultimately, the desired outcome was a patient who died a peaceful death, in the place of their choice, supported by their family. Alongside this, families who felt supported and able to cope when caring for a dying relative were also given as examples of cases where good care had been achieved. Other indicators related to the feelings of staff. It was not uncommon for respondents to cite cases where they felt they had "done a good job" or cared for someone as they would wish themselves to be cared for. These sentiments are expressed in the following quotation, which encapsulates many of the factors indicative of high quality care:

"We were able to provide a very high standard of care I feel-and his family do-and enabled this man to stay at home doing exactly what, you know, he died where he wanted to be. He was pain free and dignified and we achieved that by working with the hospice. Any voluntary agencies I could muster round any support, we used everybody. We had a truly multidisciplinary approach to this man's care. And it worked very very well. His wife was very supportive and of course the patient was, you know. It was nice; it was a privilege to look after that man because everything was set up really well. It was a nice home to work in. Nice in the sense that his wife was willing to accept people in her home. Because it's difficult isn't it when you know it's your home and you've got all these people and I think it was-I'm blowing my own trumpet really-good planning. It was I felt as if I did a good job in planning and anticipating well what they might need, and it paid off."

\section{Discussion}

Community nurses were able to articulate clearly the essential components of high quality palliative care and the circumstances that militate against this ideal. Whilst a number of key factors were identified, forming a good rapport with the family was central to the provision of effective care. The importance of the bond between the patient and nurse has been acknowledged elsewhere. ${ }^{18}{ }^{19}$ Williams $^{19}$ found that therapeutically effective care was more likely to occur in positive relationships characterised by the establishment of rapport and trust. In this respect the care needs of patients were more easily met if the nurse knew the patient. The findings of this study extend this concept to the community setting where a collaborative working relationship with the family as a whole acted as a precursor to high quality care.

Given the pivotal role played by establishing a strong relationship, the early referral of patients to the district nursing service was of primary importance. Occasions on which this did not occur could prove problematic as the nurse was intervening in a crisis situation in the absence of prior knowledge of the patient or family. Despite the fundamental nature of this requirement, respondents commonly described unsatisfactory care in the context of the late referral of patients. In this respect the study mirrors the findings of others where late referrals were highlighted as a source of dissatisfaction. ${ }^{48102021}$ Goodman et $a l^{4}$ surmised that late referrals to the service and the emphasis on the practical role of community nurses in patient care indicate that the contribution of the district nursing service is not always recognised by those who are involved in referral, notably GPs. The recent Audit Commission report ${ }^{14}$ highlights the importance of clarifying the referral criteria to the district nursing service, since currently one in 10 referrals are inappropriate and other patients are not referred at all.

This study has shown that the early involvement of the district nursing service facilitates patient care by enabling the community nurse to act as key worker in orchestrating the introduction of other services. Providing care in a supportive environment, preferably one in which there is open awareness of the patient's diagnosis, reduced the dependence on support services and enabled patients to remain at home if this was their wish. There was a widely held perception that most patients would prefer to die at home and care was seen to have failed if this was not achieved. A good working relationship with the GP was deemed as essential if inappropriate admission to hospital was to be averted.

The relationship with the GP was critical in three key respects: (1) in the early referral of patients to the district nursing service; (2) in 
maintaining contact with the community nurses to avoid the unnecessary admission of patients to an institutionalised setting; and (3) in symptom control. The role of Macmillan nurses was also valued in terms of the expertise and support they could provide.

Spending time with patients requiring palliative care was highly valued by community nurses, sometimes at the expense of other aspects of their work. Palliative care was clearly an area in which community nurses derived a great deal of job satisfaction. Nurses often described aspects of care that could be viewed as being "over and above" that required to meet the patient's immediate nursing needs. Others have identified this phenomenon-for example, Williams ${ }^{19}$ noted that additional nursing care which went "over and beyond" usual care epitomised high quality care and that these "extras" are the first things to go when time is limited.

Whilst palliative care is an area of work which community nurses have always valued, it has achieved greater significance since the transfer of some nursing duties to social care services. Palliative care is one area in which all aspects of care may be provided by the district nursing service and where the care provided is truly holistic. It is seen to legitimise aspects of care which would, in other circumstances, be defined as social care. Griffiths ${ }^{20}$ also describes the phenomenon in which terminal illness sanctions activities that might otherwise be described as illegitimate and permits nurses to "take on their more traditional pre reforms role of the total care of a person and their family in their own home". In her study she suggests that this is an area of care which has not yet been passed on to others. In this respect the findings reported by Griffiths differ from the comments made by some of the respondents in this study who indicated that the notion of holistic care provision was sometimes problematic, even for patients who were terminally ill. The firmer establishment of the division between health care and social care may explain this.

It is worthy of note that, despite the changes over the last decade, the factors associated with attaining high quality palliative care reveal a remarkable similarity to those described in earlier studies. Seale, ${ }^{8}$ in a major study of the role of community nurses and the care of the dying, drew on accounts by relatives and nurses to describe the adequacy of care. This study replicated a previous investigation in 1969. Seale's study highlighted tensions between the community nurses and GPs in areas such as pain management, with half the nurses stating that patients were not referred to them early enough. This prohibited nurses from getting to know the patient early on and establishing a relationship with them. Difficulties were encountered if nurses were brought in to manage a crisis situation or if the patient was unaware of their diagnosis. It was noted that patients were less likely to be cared for at home if relatives were unable, or did not wish, to do so. One of the major problems was lack of time for care provision with nurses expressing a strong desire to spend time with patients, build up a relationship, and provide emotional support rather than simply providing physical care. These concerns were also reflected in Bergen's review of the literature. ${ }^{9}$

Clearly, community nurses have been placed in a position in which they need to make their contribution to patient care more apparent. It has been argued ${ }^{22}$ that, if purchasers do not have a clear understanding of how a service operates, then it may not be adequately funded. Our findings suggest that many of the activities viewed by community nurses as leading to high quality care are relatively "invisible"-for example, emotional support, forming good relationships, coordination of service input. The need for clear articulation of the core components of the contribution of community nurses to high quality palliative care is therefore readily apparent.

\section{Conclusion}

Respondents related situations in which they had been able to provide palliative care in a compassionate and holistic way. It was clear that this was a situation in which staff felt a desire to provide care at a level which might be viewed as "over and above" that required to meet the patient's immediate nursing needs.

The district nursing service was viewed as central in terms of planning and coordinating care and ensuring that the services of other agencies complemented rather than duplicated care. In general, care went well if there was an open relationship which facilitated a partnership between the district nursing service, the patient, the family, and other services.

It was clear that establishing a close relationship with the family was highly prized by respondents, and situations in which this was possible proved the most satisfying in terms of achieving desirable outcomes for patients. Many of the working practices of those interviewed therefore centred on achieving this particular goal. What is also clear is that what community nurses view to be at the heart of their work - the provision of holistic care-is not always fully understood by others.

Finally, despite the changes in the district nursing service and the provision of palliative care, there are certain tenets that hold true over time with regard to what constitutes good care. Perhaps what is more surprising is that the difficulties encountered in meeting these ideals have not been resolved. This study offers a useful contribution to the body of knowledge on the provision of high quality palliative care in a community setting by community nurses. The "structures/processes/outcomes" identified in table 1 could be viewed as the first stage in the development of benchmarks for a quality review of palliative care provided by community nurses. While this standard might be viewed as a useful building block, as opposed to a comprehensive list, it is of particular value given the "bottom up" approach adopted in the identification of key factors. Further studies examining the perspective of others-for example, patients, carers, and specialist nursescould be used to augment this standard. This is particularly pertinent since the perceptions of 
patients may not be congruent with those of service providers. While not all of the factors are under the direct control of the community nurses (most notably, the family circumstances and the actions of other health care professionals), many are-for example, the manner in which care is organised. Furthermore, other influential factors are eminently suitable for audit-for example, the number of patients who are referred to the service at an early stage and the number of patients who are cared for and die in the place of their choice. Findings from such an audit may indicate why desirable levels of service are difficult to achieve and could lend weight to discussions with other services if a change in their practice is considered desirable.

1 Secretary of State for Health. The new NHS, modern, dependable. London: NHS Executive, 1997.

2 Secretary of State for Health. A first class service: quality in the new NHS. London: NHS Executive, 1998.

3 Griffiths J. An ethnographic study of district nursing work. $\mathrm{PhD}$ thesis, University of Liverpool, 1996.

4 Goodman C, Knight D, Machen I, et al. Emphasising terminal care as district nursing work: a helpful strategy in a purnal care as district nursing work: a helpful strategy in a pur-
chasing environment. $\mathcal{F}$ Advanced Nursing 1998;28:491-8.

chasing environment. F Advanced Nursing 1998; $28: 491-8$.
5 Law R. The quality of district nursing care for dying patients. Nursing Standard 1997;12:41-4.

6 Hatcliffe S, Smith P, Daw R. District nurses' perceptions of palliative care at home. Nursing Times 1996;92:36-7.

7 Department of Health. A policy framework for commissioning cancer services. Calman Report. London: Department of Health, 1995.
8 Seale C. Community nurses and the care of the dying. Soc Sci Med 1992;34:375-82.

9 Bergen A. Nurses caring for the terminally ill in the community: a review of the literature. Int $\mathcal{F}$ Nursing Studies 1991;28:89-101.

10 Bergen A. Evaluating nursing care of the terminally ill in the community: a case study approach. Int 7 Nursing Studies 1992;29:81-94.

11 Denys B. Palliative care in the community. $f$ Community Nursing 1997;11:8-12.

12 Department of Health. NHS and Community Care Act. London: Stationery Office, 1990.

13 Griffiths J. Meeting personal hygiene needs in the community: a district nursing perspective on the health and social care divide. Health Social Care in the Community. 1998;6:234-40.

14 Audit Commission. First assessment: a review of district nursing services in England and Wales. London: Audit Commission, 1999.

15 Flanagan J. The critical incident technique. Psychol Bull 1954;51:327-59.

16 Norman IJ, Redfern SJ, Tomalin DA, et al. Developing Flanagans's critical incident technique to elicit indicators of high and low quality nursing care from patients and their nurses. F Advanced Nursing 1992;17:590-600.

17 Royal College of Nursing. Quality patient care. The dynamic standard setting system. Harrow, Scutari: Royal College of Nursing, 1990.

18 Radwin LE. 'Knowing the patient': a review of a research on an emerging concept. F Advanced Nursing 1996;23:1142-6.

19 Williams A. The delivery of quality nursing care: a grounded theory study of the nurse's perspective. F Advanced Nursing 1998;27:808-16.

20 Griffiths J. Holistic nursing care for the terminally ill. $\mathrm{Br} f$ Community Health Nursing 1997;2:440-4.

21 MacDonald L, Macnair R. Your views on terminal care. 7 District Nursing 1996;4:11-3.

22 Wright S. Community nurses take on the task of selling themselves. Nursing Times 1996;92:38-40.

\section{Rapid responses}

If you wish to comment on an article published in $Q H C$, why not make use of our "rapid response" option?

Log on to our website (www.qualityhealthcare.com), find the paper that interests you, click on "full text" and send your response by email by clicking on "submit a response".

Unless the content seems irrelevant or likely to offend, it will be posted within seven days. You can retrieve it by clicking on "read rapid responses" on our home page.

The editor will decide whether also to publish it in a future paper issue.

It is hoped that "Rapid responses" will enable readers to set up a dialogue about topics in quality of health care. 